\section{The Airborne Surgical Unit}

THE limited but valuable experience which has been obtained of the feat of taking a surgical team into action with airborne troops is described by two R.A.M.C. surgeons who have organized it, Mr. C. J. Longland and Mr. L. Kessel (The Lancet, March 18, 1944, p. 381). Their article has been written "to correct the hyperbole and inaccuracy of accounts which have appeared in the lay press". Such surgical teams have been in action twice. On the first occasion it was proved that the feat could be done; the second job was a difficult one, but the team successfully established itself at night in a farm building behind the enemy's lines while a battle was going on near by. Some of the thirty-five operations performed were done $1 \frac{1}{2}$ hours after the wounds were received, and four fifths of them were done within five hours of the wounding. The team consisted of a surgeon, an anæsthetist and five other ranks, one of whom was responsible for resuscitation and two were chosen for their nursing abilities. All were, however, trained in all phases of the work. The team also had field and parachute training.

The details given of the equipment taken will interest all who have to provide transportable surgical equipment for field purposes. It was found that a light operating table or stretchers and trestles can be carried. Anæsthetics, plaster, dressings and other expendable material were put up in packs suitable for ten cases. Other items were instruments, plasma for resuscitation, feeders, bowls, trays and other ward equipment, and a sterilizer and boiled water container into which some materials could be packed. Linen thread was the basic suture material, and acriflavine tablets were found to be the most economical and useful antiseptic. Primus stoves were found satisfactory for heating, provided that several were available; but it was "distressingly and effectively proved" that ether may be a dangerous cause of fire in a theatre heated by primus stoves. Out of 150 cases, only 11 needed any anæsthetic other than pentothal; the other anxsthetic used was chloroform. For lighting, the choice fell on paraffin pressure lamps and electric headlamps.

\section{Apprentice Scholarship Scheme at Birmingham}

IN his annual report to the court of Governors of the University of Birmingham, the Vice-Chancellor (Dr. Raymond Priestley) comments on education for engineers. The University Joint Recruiting Board has been favourably impressed by engineering apprentices who have appeared before it for deferment or allocation in connexion with the Higher National Certificate in various branches of engineering. These men have entered industry either at or before the School Certificate stage, and have qualified, chiefly through evening work at technical colleges, to pass severe theoretical and practical tests. The successful candidates have impressed those whose duty it has been to interview them by their quality, grit and obvious sense of social responsibility. It has been quite clear that many of them are deserving of, and would be the better for, full-time university education, and that any university would benefit from their presence as students. Through conferences between the University of Birmingham, the Midland technical colleges and local firms, a scheme has been devised whereby the pick of the National Certificate holders in the Midlands might be admitted to the degree courses in mechanical and electrical engineer- ing of the University. Candidates who have been three years in industry and who are nineteen years old or older will be able to matriculate through an examination towards which National Certificate subjects will count. A paper designed mainly to test ability for expression in English is the only additional obstacle to be surmounted. National Certificate scholarships with full maintenance, including residence at a hostel for the three years of the degree course, have been founded already by several firms.

Dr. Priestley points out that if the full value of the apprentice scholarship scheme is to be realized, it is essential that there should be the earliest possible modernization of the engineering equipment at the University of Birmingham. An appeal is therefore being made to the engineering industry of the nation, and particularly that part of it located in the Midlands, for a quarter of a million pounds for new buildings and equipment - a modest request for the Departments of Mechanical and Electrical Engineering. Close co-operation between the university and industry is necessary, and industry must accept the view that the university cannot by itself make practical engineers, production planners, and industrial managers. The university's primary aim must remain, on the research side, original contributions to the science of engineering; on the teaching side, the utmost possible development of the personality of students and a sound grounding in the sciences that underlie engineering and the basic principles of engineering science. What is needed is more and larger faculties of technology in the universities, possibly more universities, not hybrids in which applied science is developed to hypertrophy in dangerous isolation. The Manchester College of Technology is a good example of a welldeveloped faculty of technology in a university. We need also a more equitable division of Great Britain's intellectual élite among the universities.

\section{Scientific Research and Development in India}

IN his opening address to the symposium on "PostWar Organisation of Scientific Research in India" held at Calcutta during September 27 and 28, 1943 (Science and Culture, 9, 135; October 1943), Sir J. C. Ghosh urged that the time is ripe for a critical examination of the facilities for scientific research and training that are available in India, and for drawing up plans for improving and co-ordinating such facilities. At present the agencies responsible for this work are the universities, the central institutes under the Government of India, the Imperial Council of Agricultural Research, the Indian Research Fund Association, the Board of Scientific and Industrial Research, the endowed research institutes like the Indian Institute of Science, the Indian Association for the Cultivation of Science, the Bose Research Institute, etc., and the research laboratories of industrial concerms like the Tata's. Sir J. C. Ghosh suggests an annual grant of Rs. 2.6 crores for research, and an equal grant for training research workers, as reasonable in the first three years after the War. With regard to organization, he suggests that the National Research Council of Canada rather than Russian methods may form the best model for India. Laboratories concerned mainly with shortrange programmes of research should be administered by an all-India national research council through properly constituted research committees functioning on their governing bodies. With regard to develop. 